D) Check for updates

Cite this: Food Funct., 2018, 9, 1294

\section{Interactions between wine phenolic compounds and human saliva in astringency perception}

\author{
Ignacio García-Estévez, (iD Alba María Ramos-Pineda (iD and \\ María Teresa Escribano-Bailón (iD *
}

Received 22nd December 2017, Accepted 22nd January 2018

DOI: $10.1039 /$ c7fo02030a

rsc.li/food-function

\begin{abstract}
Astringency is a complex perceptual phenomenon involving several sensations that are perceived simultaneously. The mechanism leading to these sensations has been thoroughly and controversially discussed in the literature and it is still not well understood since there are many contributing factors. Although we are still far from elucidating the mechanisms whereby astringency develops, the interaction between phenolic compounds and proteins (from saliva, oral mucosa or cells) seems to be most important. This review summarizes the recent trends in the protein-phenol interaction, focusing on the effect of the structure of the phenolic compound on the interaction with salivary proteins and on methodologies based on these interactions to determine astringency.
\end{abstract}

\section{Introduction}

Astringency has been defined by the American Society for Testing Materials ${ }^{1}$ as "the complex of sensations due to shrinking, drawing or puckering of the epithelium as a result of exposure to substances such as alums or tannins". Although the bases of the astringency mechanism are not yet well understood, they are known to be engendered by different classes of astringent compounds, including salts of multivalent metallic cations (particularly aluminum salts), dehydrating agents (ethanol and acetone), mineral and organic acids and polyphenols. ${ }^{2,3}$

\section{Mechanisms for astringency}

The word astringency is derived from the Latin ad stringem, meaning 'to bind', showing the basis of this primary chemical process. The first mechanism for astringency was proposed by Bate-Smith (1954), ${ }^{4}$ indicating that the main reaction whereby astringency develops is via precipitation of proteins and mucopolysaccharides in the mucous secretions. ${ }^{5}$ This view is still broadly assumed, although widely different opinions exist around the astringency process.

Lee and Lawless $(1991)^{6}$ proposed that astringency can be broken down into multiple sub-qualities. Their data suggested that the tactile attributes of drying and roughing were the most closely associated with astringency, implying changes in

Grupo de Investigación en Polifenoles, Departament of Analytical Chemistry, Nutrition and Food Sciences, Faculty of Pharmacy, University of Salamanca, Campus Miguel de Unamuno s/n. E37007, Salamanca, Spain.

E-mail: escriban@usal.es the texture of the oral mucosa. Green $(1993)^{7}$ also pointed to a tactile origin of the astringency sensation, mainly caused by the precipitation of salivary proteins and possibly cross-linking of proteins in the mucosa. Since some polyphenols are able to bind salivary proteins, they can form insoluble tannin-protein precipitates in the mouth, causing a loss of lubrication and increased friction in the oral cavity, which would explain the astringency. ${ }^{8}$ The most accepted mechanism to explain these facts was proposed by Siebert et al. (1996). ${ }^{9}$ Regarding this mechanism, a protein has a fixed number of sites to which tannin can bind, while each polyphenol also has fixed number of binding sites. When the total numbers of binding sites of both polyphenols and proteins are equal, the largest network and maximum precipitation will be produced. Then, depending on the ratio of protein or tannin used, different proteinpolyphenol complexes will be formed. ${ }^{10}$

The interaction process between polyphenols and peptides has been divided into three stages. ${ }^{11}$ Initially, reversible associations between the hydrophobic face of the aromatic rings of the polyphenol and the pyrrolidine ring of the proline residues of the protein give a soluble complex; in general, several molecules can bind to the same peptide. In the second stage, two peptides are cross-linked by the addition of more polyphenols that can bind to the peptide, acting as a linker between two peptides, by cooperative weak intermolecular binding interactions, leading to a larger insoluble complex. Finally, the complex aggregates spontaneously and the separation phase occurs. This 3-stage model was later confirmed and expanded by Jöbstl et al. (2004). ${ }^{12}$

Protein-polyphenol aggregates have been described as both soluble and insoluble, and the stability depends on several variables like protein : polyphenol ratios, $\mathrm{pH}$, temperature, the 
ionic strength of the solution and the types of polyphenol and protein used. ${ }^{2}$ Recently, it was suggested that there are synergistic effects between phenolic compounds, possibly due to cooperative behavior between phenolic compounds when binding proteins, which could explain why astringency is more influenced by the qualitative phenolic composition than by the total concentration. ${ }^{13,14}$

Although the precipitation of salivary proteins, namely PRPs, is one of the most accepted mechanisms, not all astringents cause salivary protein precipitation, suggesting that there must be other mechanisms implicated in astringency development. For instance, Lee and Vickers $(2012)^{15}$ studied the influence of the loss of salivary lubricity on the development of the astringency sensation. They showed that precipitation of PRPs or mucins is not a requirement for the development of astringency. Considering these results, they proposed that changes in friction or lubricity are not necessary conditions for astringency and they stipulated that direct tissue effects could be related to tannin astringency, while acid astringency could be related to a disruption of the mucus lubricating coating. ${ }^{16}$

Other approaches have suggested that astringency could be engendered by the activation of specific taste receptors ${ }^{17}$ or even by direct interactions between tannins and oral epithelial cells. ${ }^{18}$ Gibbins and Carpenter $(2013)^{19}$ proposed that the complex sensation of astringency could involve multiple mechanisms occurring simultaneously: aggregation of salivary proteins, salivary film disruption, decrease in salivary lubrication, receptor exposure and mechanoreceptor stimulation in the oral mucosal epithelium. Nevertheless, since there are no conclusive results, the scientific community is still discussing the different proposed mechanisms that explain this complex phenomenon.

\section{Salivary proteins}

Saliva is composed mainly of water, a variety of electrolytes, proteins and glycoproteins, enzymes, mucins and nitrogenous products. This complex mixture is derived predominantly from the secretions of the three-paired major salivary glands (parotid, submandibular and sublingual glands) and numerous minor salivary glands and gingival crevicular fluid. ${ }^{20}$ Salivary proteins are usually divided into several major classes, including proline-rich proteins (PRPs), statherin, cystatins, P-B peptide, histatins and mucins. ${ }^{21}$ Among them, statherin, which is abundant in tyrosine residues and phosphorylated at some serine, has been shown to play an important role in lubrication, whereas cystatins are more related to a protective role as a result of inhibition actions against bacterial and viral cysteine proteases. ${ }^{20}$ Histatins are small histidine-rich proteins (mainly His 1, His 3 and His 5), which are minor proteins in saliva that have been reported to exhibit antifungal activity. ${ }^{20}$ Mucins are high molecular weight proteins that account for almost $20 \%$ of total saliva proteins, ${ }^{20,21}$ and consist of $70-80 \%$ carbohydrate and whose main function is related to lubrication, hydration and protection of the oral cavity. ${ }^{20}$ However, with regard to astringency, proline-rich proteins (PRPs) seem to be the most important component of saliva, since their interaction with tannins has been thought to be at the origin of astringency. ${ }^{22}$ PRPs are a heterogeneous family characterized by a high content of proline residues (25-42\%), which in turn can be divided into acidic, basic and basic glycosylated proteins (aPRPs, bPRPs, gPRPs, respectively). ${ }^{23}$ More than 11 human bPRPs and more than 5 aPRP isoforms have been identified; multiple PRPs originating from the same gene through allelic variations, differential splicing and post-translational cleavage of larger precursors can be found in saliva, ${ }^{20}$ which explains the complexity of saliva proteome. The main differences among the major families of salivary proteins, the PRPs, are related to their charge and to the presence or absence of glycosylation in their structure. bPRPs and aPRPs show a similar C-terminal region but they differ in their $\mathrm{N}$-terminal region, which in the case of aPRPs is highly acidic mainly due to the presence of aspartic and glutamic acid residues. Moreover, aPRPs are usually phosphorylated in some serine residues. ${ }^{23}$ The $N$ - and $O$-glycosylations of bPRP give rise to the family of gPRPs. In these proteins, $N$-glycan moieties are attached to the amide group of asparagine residues, whereas there is not a consensus on the sequence for $O$-glycosylation. ${ }^{23}$ Another salivary protein showing a high content of proline residues ( $c a .50 \%$ of its sequence) is $\mathrm{P}-\mathrm{B}$ peptide. P-B peptide shows some similarities to statherin (its structure is more similar to the statherin structure and it is a product from a specific gene very close to the statherin gene), ${ }^{21}$ and unlike PRPs, it specific biological role is still not well defined. ${ }^{24}$ In fact, the P-B peptide shows several differences in its structure when compared to other PRPs, such as the presence of several hydrophobic regions (rich in Phe, Leu and Ile). As such, although the P-B peptide could be included in the PRP family due to the high content in proline residues, its peculiarities make it worth considering by itself.

Most astringency studies in the literature related to salivary proteins are focused in the PRP family. The molecular basis of astringency development has been widely studied using model bioassays with PRPs and tannins by means of several techniques such as spectrophotometry (mainly fluorescence), nephelometry, dynamic light scattering (DLS), NMR and mass spectrometry. Among the PRPs, the bPRP family is the most studied since it has been reported to show high affinity for tannins, ${ }^{25}$ being very effective in forming insoluble complexes with tannins. ${ }^{26}$ Moreover, this family has no other specific functional role than binding polyphenols, thus mitigating the possible deleterious effects of these compounds. However, recent studies have reported, both in vitro and in vivo, a greater interaction between certain polyphenols and acidic PRPs or $\mathrm{P}-\mathrm{B}$ peptide, compared to bPRPs. ${ }^{27-29}$ These controversial results indicate that there is still a lack of information about the real affinity of each family of salivary proteins toward the different polyphenols usually involved in astringency development.

\section{Protein-phenolic compound interaction}

As has been explained before, the mechanism that most widely accepted as the most important in astringency develop- 
ment is the interaction between salivary proteins and phenols in the mouth. Several works have shown good correlations between perceived astringency and the ability of the astringent compounds to interact/precipitate proteins. ${ }^{30,31}$ This relationship between the interaction with protein and the astringency properties of some compounds has also been proved using model proteins instead of salivary proteins. Even with using model proteins, a significant correlation between protein precipitation, after the interaction with phenolic compounds, and the perceived astringency has been reported. For instance, it has been proved that there is a correlation between the precipitation of proteins such as bovine serum albumin (BSA), alphaamylase, gelatin or ovalbumin and the astringency of phenolic compounds determined by a sensory panel. ${ }^{32,33}$

The compounds that interact with salivary proteins have been named tannin-like compounds on the basis of the definition of a tannin as a compound that has the ability to interact with and/or precipitate proteins. Tannins are a group of structurally very diverse polyphenols that are usually divided into hydrolysable and condensed tannins. Hydrolysable tannins are glucoside derivatives from gallic (gallotannins) or ellagic acid (ellagitannins) that are extracted from oak wood during winemaking or aging, or added via oenological tannins to wine. Condensed tannins are oligomers and polymers of flavan-3-ol [((epi)catechins and (epi)gallocatechins)], also known as proanthocyanidins, which are present in wine because of their extraction from the grape skin and seed. Since these compounds are considered to be mainly responsible for the astringency in wine, they are the most studied, although as will be discussed later, other wine phenolic compounds can play an important role in the astringency development through the association between phenol compounds and proteins.

In general, molecular association is usually related to the formation of aggregates of molecules, which could be soluble or non-soluble; therefore, the interaction between phenols and proteins can lead to the precipitation (or not) of salivary proteins, thus importantly affecting astringency in different ways, as will be explained later. These differences could be related to the different mechanisms that can be involved in the phenolprotein interaction, which in turn may be affected by the kinds of bonds implicated in the interaction. Thus, the cross-links established between phenols and proteins could involve mainly two kinds of bonds, i.e., hydrophobic interactions and hydrogen bonds. Hydrophobic interactions occur via van der Waals-London interactions between the most apolar amino acids and the benzene rings of the phenolic compounds. ${ }^{12,34,35}$ Murray and co-workers ${ }^{36}$ have demonstrated by NMR that in the case of pentagalloylglucose and two model synthetic peptides, the main binding sites on the peptides are proline residues together with the preceding amide bond and amino acid, through hydrophobic interaction involving $\pi-\pi$ bonding between the galloyl ring and the pyrrolidine ring face containing the $\mathrm{C} \alpha$ proton of proline. Thus, it seems that prolines are the main binding sites of proteins with regard to hydrophobic interactions, thus explaining the importance of
PRPs, in which the first residue of the sequences rich in proline are the preferred binding sites. This hypothesis has been supported by studies reporting that the interaction between phenolic compounds and proline rich protein/ peptides has a number of binding sites related to specific associations that match with the number of hydrophilic domains involving short proline repeats in the protein chain. ${ }^{37,38}$

On the other hand, polar interactions occur via hydrogen bonds among the carbonyl and amino groups of proteins and the hydroxyl groups of phenolic compounds. These kind of bonds have been proposed to play a stabilizing role in the formation of the protein-tannin aggregates. ${ }^{11}$ Moreover, other kinds of bonds have been described in the literature that may be involved in the protein-tannin interaction, but play a less important role in the formation of aggregates, such as covalent bonds, which might be formed between the quinone forms of phenolic compounds (usually resulting from the oxidation of the latter) and the amino or thiol groups of proteins. ${ }^{39}$ Moreover, ionic bonds could be established between the cationic sites of proteins and the anionic phenolates formed by phenolic compounds, although the possibility of this kind of bond occurring is low since at the $\mathrm{pH}$ at which interaction usually occurs, the phenolic compounds do not have charged groups (except for anthocyanins, which can have positive charges). ${ }^{34,35}$ However, evidence for hydrophobic and hydrogen bonds, which are the main bonds driving the proteintannin interaction, has been obtained by different techniques. For instance, isothermal calorimetry (ITC) allows the study of the interaction through the energies involved. McRae and coworkers $^{40}$ have proved that the initial binding reaction between tannins and protein is temperature-dependent, which can indicate a competition between exothermic and endothermic binding interactions. The strength of the endothermic component of this initial binding interaction increases with temperature, which is consistent with hydrophobic interactions, since these interactions have to break the structured water around the apolar residues of tannins, which requires energy. Thus, hydrophobic interactions are often observed to be endothermic at relatively low temperatures, but with negative $\Delta G$, which implies an important increase in entropy as a result of the disarrangement of the structured water around the compounds and protein conformational changes. ${ }^{41}$ On the contrary, exothermic processes with a decrease in entropy that are non-dependent on temperature are related to hydrogen bond formation, possibly supplemented by additional weaker van der Waals interactions. ${ }^{40}$ However, these processes usually take place at the same time, and there is some co-operativity between these two kinds of bonds.

The global process of phenol-protein interaction involving those bonds is a complex process that has been proposed to occur in three main stages. ${ }^{11}$ This hypothesis is widely accepted and it has been proposed to be coincident with the time course of astringency. ${ }^{12}$ The first stage has been assumed to be the formation of small protein-phenol soluble aggregates. In this step, the multidentate phenol compounds can bind to several sites on the protein, which can cause the 
change in the protein structure from a randomly coiled protein to a more compact structure around the phenolic compounds. ${ }^{37,38}$ Hydrophobic interactions have been proposed to be mainly responsible for this first step although as explained above, the hydrogen bonding effect assists in stabilizing the complexes. In the second stage, these small aggregates formed by phenol-protein complexes self-associate via cross-links, leading to the formation of complex aggregates. In this second stage, nonspecific interactions are predominant and hydrogen bonds have been proposed to be responsible for the stabilization and the strengthening of the complexes. Finally, in the third stage, these large sized complexes precipitate as a result of the coalescence. Thus, phenolic compounds first link to the peptide via its hydrophilic sites in a more specific interaction to form relatively small complexes that then aggregate by themselves via mainly hydrophilic non-specific interactions to first form highly soluble aggregates, then coalesce and precipitate. However, there are studies reporting that in the case of small peptides such as $\mathrm{IB}_{14}$, tannins bind to the hydrophilic side of the saliva peptide, suggesting that the major interaction forces are governed by hydrogen bonds between the carbonyl functions of the proline residues and both the phenol and catechol $\mathrm{OH}$ groups of the phenolic compounds, whereas the hydrophobic interactions play a secondary role. ${ }^{42}$ These authors also point out the importance of the medium in which the studies are performed, since the delicate balance between the hydrophobic and hydrophilic forces may be strongly depend on solvent. Moreover, the main driving forces are also dependent on the structure of the protein and on the concentration and chemical nature of the phenolic compounds and, within each sub-class of phenolic compounds, on their molecular weight, structure, and functional groups.

With regard to the structure of salivary proteins, there are differences in the protein affinity towards phenolic compounds, depending on the salivary protein. Recent studies have indicated that the $\mathrm{P}-\mathrm{B}$ peptide is the salivary peptide showing the highest affinity to both hydrolysable and condensed tannins. ${ }^{43,44}$ Regarding PRPs, it seems that the protein glycosylation is the main factor that can affect the interaction. It has been proposed that the oligosaccharide moiety of glycosylated PRPs (gPRPs) allows the maintenance of a more open conformation of the protein structure, thus making the formation of large aggregates, which would lead to protein precipitation, difficult. In fact, it was demonstrated that for a low tannin concentration, gPRPs formed soluble tannins in contrast to the precipitation of other PRPs such as aPRPS, whereas at higher tannin concentrations, the increase in the number of tannins linked to proteins led to the precipitation of gPRPS. $^{28,45}$ This is related to the lower hydrophobicity of gPRPs as a result of the oligosaccharide moiety that makes them more soluble. However, the increase in the number of linked tannins increases the hydrophobicity of the complexes, leading to their aggregation and precipitation; ${ }^{45}$ thus, protein complexes can be soluble or insoluble. Although, as explained above, it is assumed that the precipitation of proteins is the main mechanism responsible of the loss of saliva lubrication ability thus leading to astringency, there are studies indicating the possibility that the formation of soluble aggregates can also be involved in the astringency sensation. ${ }^{27}$ It has been demonstrated that there are compounds that are unable to precipitate proteins, but are proved to be astringents. ${ }^{46}$ It seems therefore that astringency is better correlated with the strength of phenol-tannin interaction than with the ability of phenol compounds to precipitate proteins. ${ }^{47}$

Regarding phenolic compounds, the importance of the chemical nature (hydrolysable or condensed tannins, flavonols, anthocyanins, etc.) and structure (molecular weight, substituents and presence of galloylation, etc.) on their ability to interact with proteins will be discussed in the next section.

There are many phenolic compounds in wine that have shown the ability to interact with proteins, thus being able to affect wine astringency. Hydrolysable tannins, as will be discussed later, have shown an important affinity for proteins, but they are usually minor compounds in wine since they are only present when winemaking and/or aging are performed using oak tanks or barrels, or when oenological tannins are added to wine. Because of this, they are probably minor contributors to wine astringency. Other phenolic compounds extracted from grapes, such as phenolic acids, flavonols or anthocyanins have shown different affinities towards protein, so although they can represent important percentages in the total phenolic composition of wines, their contribution to wine astringency could be limited. Flavanols, also known as condensed tannins, have shown a great affinity towards proteins and they are major constituents in wine, since they are extracted from grape skin but mainly from grape seed during winemaking; consequently, this group of compounds is one of the most important among phenolic compounds in wine. For these reasons, although most of the phenolic compounds in wine have shown astringent properties, it is assumed that wine astringency is primarily driven by flavanols. ${ }^{22}$

\section{Flavan-3-ols}

Influence of the flavanol structure in perceived astringency. Flavan-3-ols are a group of polyphenolic compounds formed by the condensation of monomeric units of (epi)(gallo)catechin (Fig. 1). These compounds are also known as proanthocyanidins since their acidic hydrolysis leads to anthocyanidins. Depending on the anthocyanidin formed, this group is divided into procyanidins, which lead to cyanidin and whose structures are formed by (epi)catechin, and prodelphinidins, which lead to delphinidin and can be formed by both (epi)catechins and (epi)gallocatechins moieties. Moreover, these compounds are usually considered as monomers, oligomers or polymers depending on their polymerization degree, and galloylated or not galloylated depending on the presence or absence of gallic acid esterified in the structure.

It has been reported that flavan-3-ols can induce a puckering astringent sensation in the oral cavity at relatively low taste threshold concentrations. ${ }^{48}$ This astringency can be related to the widely described ability of these compounds to interact with salivary proteins. For instance, Kallithraka et al. have 


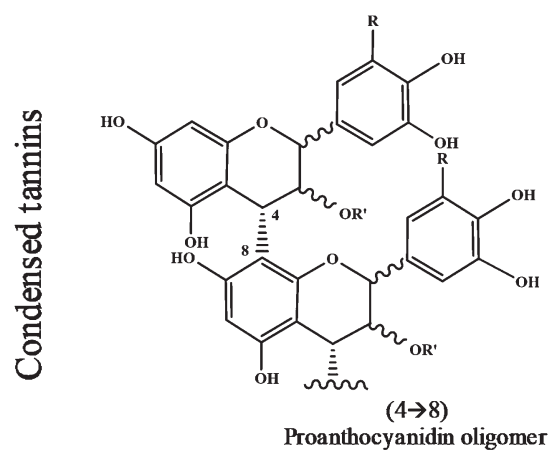

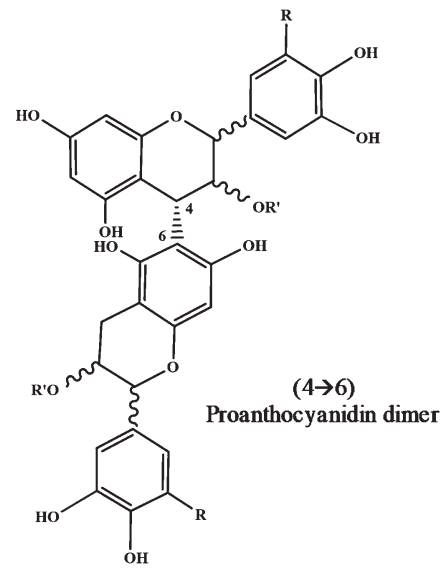<smiles>[R9]c1c(Br)cc(-c2oc3ccccc3c(=O)c2O)cc1Br</smiles>

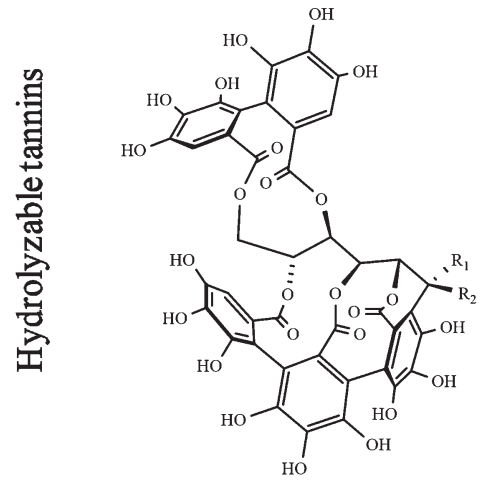<smiles></smiles><smiles>[R]c1cc(C(=O)O)c([2H])c([2H])c1[2H]</smiles>

Castalagin $\mathrm{R}_{1}: \mathrm{OH}, \mathrm{R}_{2}: \mathrm{H}$ Vescalagin $\mathrm{R}_{\mathbf{1}}: \mathbf{H}, \mathrm{R}_{2}: \mathrm{OH}$

Pentagalloylglucose (PGG)<smiles>COc1cc2c(O)cc(O)cc2[o+]c1-c1cc(O)c(O)c(O)c1</smiles>

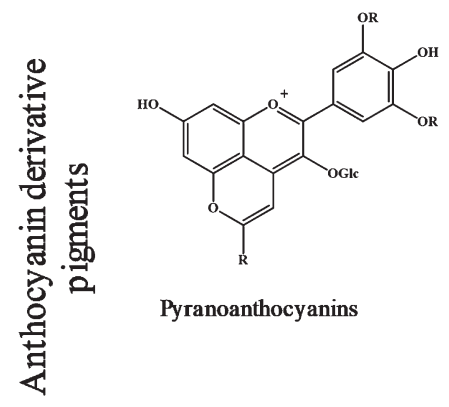

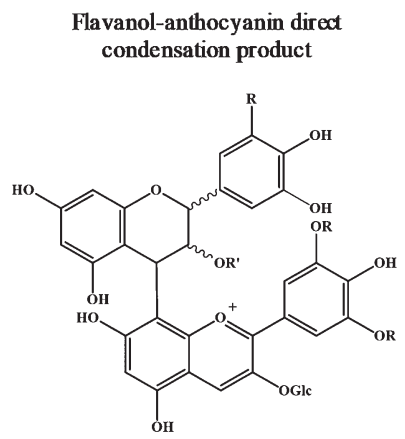

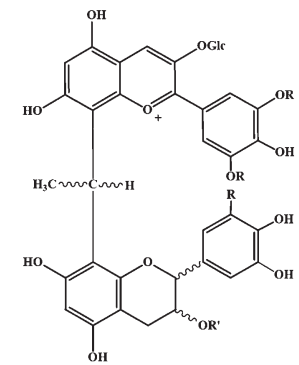

Anthocyanin-flavanol acetaldehyde-mediated condensation products

Fig. 1 Chemical structure of the main phenolic compounds related to wine astringency.

observed the disappearance of salivary proteins when mixed with flavanol extracts from seeds, which are mainly composed by procyanidins, ${ }^{49}$ and the formation of new peaks when analysing the mixtures by HPLC, which were attributed to new soluble aggregates between procyanidins and salivary proteins. The formation of soluble compounds is related to low tannin/ protein ratios. These soluble aggregates were also detected when B3 and B2-gallate interacted with salivary proteins, and it was observed that the aggregation process was influenced by tannin and protein polarity. ${ }^{50}$ Moreover, the study of the evolution of the soluble aggregates with time has confirmed the 3-step process proposed for the protein-tannin interaction. ${ }^{51}$ Furthermore, it has been reported that astringency elicited by the mixture of flavanols is more intense and persistent than that elicited by one flavonol isolated at the same concentration, indicating a synergistic effect. ${ }^{13,14}$

Regarding the interaction of flavanols with individual salivary proteins, there are significant differences among the results reported in the literature. Some authors point out that aPRP and gPRP do not interact with a mixture of flavanols, whereas bPRP (and the deglycosilated form of gPRP) formed insoluble complexes with these tannins. ${ }^{26}$ In the same way, bPRPs were involved in a greater number of aggregates with procyanidins dimers, followed by histatins and statherins, whereas aPRPs and gPRPs formed fewer soluble aggregates regardless of the tannin tested. ${ }^{50}$ Other studies showed that the procyanidin C2 trimer only interacts with aPRPs and statherin, leading to soluble complexes with the former, ${ }^{10}$ 
whereas bPRPs do not interact with procyanidins and gPRPs only interact at high levels of procyanidins. ${ }^{52}$ The use of different procyanidin extracts in the different studies can be the reason for these differences, suggesting that the flavanol structure can determine its behavior regarding protein interaction.

As already mentioned, the phenol structure primarily affects protein-phenol interactions. Regarding flavanols, the main structural characteristics affecting the interaction with proteins are related to the molecular weight, the interflavanic bond, the presence of galloylation and the substitution pattern or the B-ring. Overall, it seems that flavanols presenting compact conformations showed lower affinity to proteins than those with an extended conformation, which allows them to bind the proteins in more sites. This was proved since procyanidin dimer B2, which has a more extended conformation, showed a higher affinity towards salivary proteins than dimers B1, B3 and B4, which showed more compact structures. ${ }^{53}$

Degree of polymerization and interflavanic bond. Monomeric flavanols have been proved to induce the astringent sensation when tasted, although differences were reported among them. It seems that epicatechin was more astringent than catechin and showed a persistent, drying, unripe and harsh astringency, which is related to more unpleasant sensations than those reported for catechin. ${ }^{54}$ Regarding molecular weight, the astringent taste threshold decreased from monomeric to dimeric and trimeric flavanols, indicating that the more polymerized the flavanols are, the greater their astringency. ${ }^{48}$ This trend was supported by studies about the protein precipitation by interaction with different molecular sized flavanols. ${ }^{55}$ The ability of the procyanidins to bind PRPs increased with the average molecular weight, and the amount of insoluble aggregates increased with the degree of polymerization of the procyanidins. Since procyanidins can act as polydentate ligands, the greater the molecular weight, the greater the number of potential binding sites in the procyanidin, which can explain the greater ability of the more polymerized $\operatorname{tannins}^{55}$ to interact with proteins. Results obtained by Kilmister and collaborators support a model for the precipitation of proteins by proanthocyanidin, where increased oligomer size enhanced the opportunity for cross linkages between proteins, ultimately forming sedimentable complexes. According to these authors, larger proanthocyanidins bound to the protein are more solvent exposed than their smaller counterparts, increasing the opportunity for protein-tanninprotein crosslinking. ${ }^{41}$ Nevertheless, the relationship between molecular size and affinity towards proteins is not direct, and some factors should be taken into account. On the one hand, when increasing the molecular weight, hydrophobic parts may be less accessible, and tannins become more inflexible limiting the contact with the protein, so tannins with relatively small differences in their polymerization degree may not show differences in their ability to interact with proteins. ${ }^{41}$ Besides, the solubility of highly polymerized condensed tannins is low, which can lead to their self-precipitation before interaction. On the other hand, it has been proposed that astringency is more affected by the qualitative composition of the structure than by their degree or polymerization. ${ }^{56}$ It seems that there is a positive relationship between flavanol astringency and high contents of epicatechin subunits in extension positions and gallocatechin subunits in terminal positions in the proanthocyanidin structure. In contrast, the levels of epigallocatechin in the protein structure are negatively correlated with astringency. ${ }^{56}$

Regarding the flavanol linkage, the two main interflavanic bonds described (C4-C6 or C4-C8, Fig. 1) seem to influence the astringency; however, the results reported are quite contradictory. Whereas from a sensorial point of view it seems that C4-C6 dimers are more astringent than $\mathrm{C} 4-\mathrm{C} 8$ dimers, ${ }^{57}$ nephelometric studies pointed out that $\mathrm{C} 4-\mathrm{C} 8$ dimers have greater tannin specific activity for PRPs than their counterparts with a C4-C6 linkage. ${ }^{55}$ Moreover, it seems that there could be a complex relationship between the structural linkage of proanthocyanidins and their molecular size with regard to their ability to precipitate proteins. ${ }^{58}$

Galloylation. Galloylation generally increases the affinity of flavanols towards proteins ${ }^{59}$ and consequently, the astringency. The astringency threshold and taste activity of galloylated monomers indeed reveal that they are more astringent than their corresponding non-galloylated monomers. ${ }^{60}$ The presence of galloyl groups allows the flavanols to have a great number of possible binding sites, which increases the tannins ability to bind to proteins. In fact, the studies performed by Charlton and co-workers ${ }^{61}$ about the interaction of a model proline-rich peptide and EGCg by NMR showed that both the A ring and D ring strongly interact with proline residues of peptide, whereas the B ring seems to interact with the arginine side chain. According to these authors, in the case of nongalloylated flavanols, rings A and B are the only sites susceptible to interacting with proteins through hydrophobic interactions, whereas galloylation makes it possible that the D ring can play an additional role.

Poncet-Legrand and collaborators also observed that catechin or epicatechin interactions with poly(t-proline) are negligible compared to those observed in the case of galloylated monomers. ${ }^{62}$ Similarly, Li and Hagerman have demonstrated that both the flavan-3-ol and the galloyl group of EGCg are essential for interacting with protein through specific hydrophobic bindings, whereas EGC binds in a weaker and nonspecific way. These authors pointed out a critical role played by the galloyl moiety, which involves hydrogen bonds with the peptide thus stabilizing and strengthening the interaction. ${ }^{63}$

Moreover, the effect of the galloylation on the affinity towards protein depends on the structure of the non-galloylated flavanol. It has been reported that the presence of the galloyl group esterified on the C-3 hydroxyl group of both the EC and B2 procyanidin dimer increased their affinity for proteins, but the effect in the case of dimer is weaker, probably as a result of the more compact structure. ${ }^{64}$

B-ring substitution pattern. Flavanols are divided into two main groups, depending on the B-ring substitution pattern: dihydroxylated B-ring flavanols (catechins, which polymerize 
leading to procyanidins) and trihydroxylated B-ring flavanols (gallocatechins, which are present in the prodelphinidins structure). In grapes, procyanidins are commonly found in seeds and skins, while prodelphinidins are exclusively located in skins. It seems that the number of hydroxyl substituents present in the B-ring of the flavanic nucleus is important in the interaction with salivary proteins and the development of astringency perception. Regarding protein interaction, gallocatechins showed a higher binding affinity than catechins. ${ }^{65}$ According to sensory analysis, catechins are more astringent, dry, rough, unripe, and persistent than gallocatechins, whereas the latter are smoother, more velvety, and viscous. Molecular dynamics simulations have shown that catechins bind to a human salivary proline-rich peptide IB714 (commonly used as representative peptide of saliva) faster than gallocatechin and this interaction is maintained for longer. ${ }^{66}$ Thus, it seems that the astringency elicited by prodelphinidins is more desirable than that perceived when tasting procyanidins, which is in accordance with the preference of winemakers for the tannins from grape skins instead of those from grape seeds. Further studies about the effect of molecular size on the ability of prodelphinidins to interact with salivary protein are needed, but the difficulty in obtaining isolated prodelphinidins with higher polymerization degrees makes it difficult to perform this kind of research.

\section{Hydrolyzable tannins (gallo- and ellagitannins)}

Hydrolyzable tannins are present in wine from different possible sources such as the oak wood of the tanks or barrels employed during winemaking, the addition of oenological tannins and the extraction from cork. In any case, two kinds of hydrolysable tannins can be found in wine, namely, ellagitannins, in which acid hydrolysis leads to ellagic acid, and gallotannis, which form gallic acid after hydrolysis. The main representative structures of ellagitannins are castalagin and vescalagin, whereas pentagalloylglucose (PGG) or tannic acid can be used as representative gallotannins. According to several works, ${ }^{44,58,67}$ hydrolysable tannins show higher affinity towards proteins than condensed tannins; however, other authors pointed out a higher affinity for condensed tannins. ${ }^{68}$ The significant variability in the structures in both groups could be the reason for these discrepancies. Moreover, it has to be taken into account that the precipitation of proteins is not always directly related to the astringent properties of phenolic compounds. With regard to hydrolysable tannins, it seems that the interaction of salivary proteins with gallotannins is stronger than with ellagitannins, ${ }^{69}$ and that the affinity toward proteins increases with the galloyllation of the tannin, ${ }^{69}$ which is important in the case of gallotannins. Nevertheless, the gallotannins are less important than ellagitannins for wine astringency due to their lower levels. In fact, recent studies reported that differences in the ellagitannin content of wines could significant modify the astringency perception. ${ }^{70}$ Among the ellagitannins, it seems that depending on the structure, the perception of the astringency is different. According to the data reported by Glabasnia and Hoffman and co-workers ${ }^{68,71}$ it seems that the monomers, castalagin and vescalagin, are less astringent than the corresponding pentose derivatives, grandinin and roburin E. However, vescalagin and castalagin showed similar thresholds to ellagic acid when astringency was evaluated, and higher than the corresponding dimers, roburins A-D. ${ }^{71}$ Regarding monomeric ellagitannins, it seems that castalagin shows a higher affinity towards salivary proteins than vescalagin, which can be related to the lower hydrophobicity of the latter. ${ }^{44}$

\section{Flavonols}

Flavonols are the main constituents of wines that have been related to bitter sensations. However, they can also participate in the astringency of wines, since they have been proved to have some influence on the astringency perception in other foods, such as legumes. ${ }^{72}$ The direct influence of flavonols on wine astringency through protein interaction has not been deeply investigated. Regarding the flavonol structure, Xiao and co-workers proved that the B-ring hydroxylation of flavonols significantly affected the binding process. In general, the binding affinity increases with the number of hydroxyl groups on the B-ring. These authors have postulated the important role of hydrogen bonds in the flavonol interaction with BSA. ${ }^{73}$ These authors also pointed out that the glycosylation of flavonols reduces their ability to bind proteins such as BSA. $^{73}$ However, Hufnagel and Hofmann have demonstrated that flavonol glucosides can play an important role in wine astringency, mainly in the development of the degree of velvetiness. In the same way, recent studies carried out by Ferrer-Gallego and co-workers indicated that wine becomes more astringent, rough, green, dry and persistent when quercetin 3-O-glucoside is added, which has been related to the ability of this compound to interact with human salivary proteins. ${ }^{74}$ Molecular dynamics simulation studies between this compound and a model peptide ( IB9 $_{37}$ ) indicated that the interaction occurs mainly by hydrophobic contact $(\pi-\pi$ stacking and van der Waals interactions) between the planar surfaces of polyphenol and the ring planes of several amino acids such as Pro, Phe, Tyr, Trp. These hydrophobic bonds are strengthened by hydrogen bonds involving numerous hydroxyl groups from the phenolic compound. ${ }^{74}$

\section{Other phenolic compounds}

Anthocyanins and derived pigments. Regarding anthocyanins, there is a lack of research about their real role in the development of astringency via protein interaction. Vidal and co-workers showed that neither free anthocyanins nor anthocyanin-flavanol adducts significantly contribute to wine astringency. Only the latter could slightly contribute to astringency through their flavanic composition in a similar way to proanthocyanidins. ${ }^{75}$ These compounds have always been considered to play an indirect role in astringency through the formation of derivative pigments involving flavanols, thus modifying both the levels and the structure of flavanols in wine, which affect wine astringency. However, Ferrer-Gallego and collaborators $^{76}$ have recently demonstrated that anthocyanins 
are able to interact with saliva proteins. They observed that anthocyanin glucosides interact with salivary proteins, in particular with aPRPs, forming soluble aggregates that barely induce astringency perception. Specifically, different aPRPanthocyanin aggregates were identified with an anthocyaninprotein stoichiometry ranging from $6: 1$ to $7: 1$. Likewise, it has been reported that pyranoanthocyanins can interact with salivary proteins, mainly those pyranoanthocyanins that show in their structures flavanol or catechol moieties, and also the simplest pyranoanthocyanin, vitisin B. ${ }^{77}$ These results again indicate the possibility that anthocyanins indirectly affect the development of astringency, but in this case, by hindering the interaction between the proteins and other polyphenols such as flavanols.

Phenolic acids. The possibility that phenolic acids affect the perceived astringency has also been raised. Both, hydroxybenzoic and hydroxycinnamic acids seem to contribute to the puckering astringency, although the latter at lower thresholds. ${ }^{48}$ This hypothesis has been supported by sensorial studies $^{78}$ that report how these compounds could act as sensory-active compounds contributing to wine astringency. Moreover, a synergistic effect, named 'co-astringency', between these phenolic acids and flavanols has been postulated in the development of the astringency. According to this, the mixtures of phenolic compounds are more astringent than the one isolated phenolic compound at the same concentration. ${ }^{78}$

\section{Other factors influencing phenol-protein interaction}

The interaction between phenolic compounds and proteins is also affected by other factors. For instance, the $\mathrm{pH}$, the ionic strength or the ethanol content of wine can influence this interaction since they can impact the establishment of both hydrophobic interactions and $\mathrm{H}$-bonds between the phenolic compounds and the proteins. ${ }^{79}$ Moreover, polysaccharides can disrupt or modify the interaction between proteins and phenolic compounds, then avoid the aggregation or the precipitation of proteins. ${ }^{80}$

It has been reported that $\mathrm{pH}$ has an important effect on the ability of proteins to interact with phenolic compounds, since both the formation of aggregates and the astringency perception is increased at low $\mathrm{pH}$ values. ${ }^{79,81,82}$ Although wine $\mathrm{pH}$ usually ranges between 3.0 and 4.0, wine astringency perception varies as a result of that small difference. It seems that $\mathrm{pH}$ can induce changes in the ionic behavior of both phenolic compounds and proteins, thus explaining the differences in aggregation. ${ }^{81}$ Likewise, the size and the polydispersity index of the protein-phenolic compound aggregates increase with the ionic strength, leading to precipitation. ${ }^{83}$ Increasing ionic strength implies an increase in the hydrophobic interactions, which are driving forces in the formation of protein-phenolic compound aggregates. ${ }^{83}$

With regard to ethanol, it is widely accepted that higher ethanol levels in wine imply a decrease in astringency perception, which could be due to the lower formation of proteinphenolic compound aggregates when ethanol concentration is increased. ${ }^{81,83}$ Ethanol can modify not only the solubility of both protein and phenolic compounds, but also the hydrophobic interactions between these compounds, which can explain the formation of less aggregates or of low-molecularsize aggregates. ${ }^{83}$ Wine polysaccharides have also shown the ability to importantly affect the formation of these aggregates, which can explain their ability to modulate astringency. ${ }^{84}$ Two different mechanisms can explain this fact. ${ }^{85}$ On the one hand, polysaccharides can compete with proteins towards the interaction with phenolic compounds. In fact, it has been reported that different polysaccharide families can interact with phenolic compounds. ${ }^{86}$ On the other hand, the formation of ternary aggregates including protein, phenolic compounds and polysaccharides is also described as one possible mechanism that avoids protein precipitation since it can increase the solubility of aggregates in the medium, thus modulating the astringency perception. ${ }^{85}$ Both mechanisms are possible and the efficiency of each polysaccharide for interacting or forming aggregates with proteins and/or phenolic compound is dependent on the protein and phenolic compound structure. ${ }^{87}$ Since the polysaccharide composition of wines depends on the grape characteristics, the winemaking procedure and on the yeast employed, the modification of most of the red wine oenological steps during wine making and aging, namely grape ripening, maceration and fermentation, ageing, fining, clarification and filtration, can be employed for modulating the polysaccharide composition of wines and therefore their astringency. ${ }^{88}$

\section{Methodologies for astringency determination}

Due to the complexity of the astringency sensation, it is not easy to find a non-subjective methodology for measuring and characterizing it; as such, sensory analysis is still the most used method for the determination of astringency. However, new approaches using different instrumental techniques have been developed for solving several drawbacks related to sensory analysis. These new methodologies aim to unravel the astringency mechanisms and/or to predict the astringency sensations elicited by different compounds, which may allow the provision of an objective explanation for the astringency of different foods and beverages such as wines.

\section{Sensory analysis}

Sensory analysis requires a sensory panel comprised of 6-20 people that must have been subjected to training using a set of reference compounds and descriptors, in order to familiarize them with the astringency sensation and terminology and to standardize the criteria used for evaluating (quantitatively and qualitatively) astringency. Different scales have been employed for quantifying astringency, from the simplest linear magnitude estimations to more complex alternatives involving nonlinear spaces, the latter usually providing better results in astringency quantification. ${ }^{89}$ Among these alternatives, the Labeled Magnitude Scale (LMS) was introduced by Green and 
co-workers for rating perceptual magnitudes related to taste or aroma. ${ }^{7}$ This scale is a quasi-logarithmic scale with verbal label descriptors ranging between "barely detectable" to "strongest imaginable" that is not affected by the ceiling effect, thus improving other scales..$^{90}$

Qualitatively, it seems that to divide astringency into different sub-qualities is helpful for characterizing it. The terminology traditionally employed (astringent, puckering, roughing, drying...) can turn out to be quite general and insufficient and for this reason, Gawel and co-workers ${ }^{91}$ proposed a structured vocabulary for assisting tasters in the interpretation of the mouth-feel sensations elicited by red wines. These authors suggested the terms particulate, drying, harsh and unripe for grouping the negative sub-qualities of astringency, whereas the terms surface smoothness, complex and dynamic would group the positive ones $;{ }^{91}$ thus, it seems that sensory analysis allows a comprehensive description of astringency. In fact, it has been possible to develop predictive models for astringency from sensory results. ${ }^{92}$ However, sensory analysis shows important drawbacks: it is time-consuming, expensive and it usually leads to important standard deviations in the determination even when trained panellists are involved, since astringency perception is highly subjective. ${ }^{93}$ The use of instrumental techniques for determining astringency mainly tries to solve the latter issue.

\section{Instrumental analysis}

Most of the instrumental analyses employed for assessing astringency in wines are based on the premise that the key mechanism for astringency development is the interaction between salivary proteins (namely PRPs) and different compounds (mainly tannins and other phenolic compounds). For this reason, the simplest and most used approaches for assessing the astringency properties of phenolic compounds evaluate their ability to interact with proteins. This is the basis of the gelatin index, which measures the extent of precipitation of phenolic compounds by means of a gelatin solution. The main limitation of this method is related to high variability of the results obtained mainly because gelatin is a complex and non-standardized mixture of proteins. ${ }^{33}$ Moreover, it has been proven that this method does not provide good results for high levels of tannins. ${ }^{94}$ For this reason, other commercial proteins showing more similarities to salivary proteins are used for evaluating astringency. Among them, the most employed are bovine serum albumin (BSA) and $\alpha$-amylase obtained from porcine pancreas, the latter showing a high degree of homology to salivary $\alpha$-amilase. ${ }^{95}$ The use of these proteins for assessing the astringency of different compounds has provided successful results from a quantitative point of view. ${ }^{33,96}$ However, in order to be close to the real conditions in the astringency development, recent studies have used purified salivary proteins (SP) for assessing astringency. ${ }^{44,97}$

Moreover, the precipitation of salivary proteins has been studied by means of different techniques, such as SDS-PAGE electrophoresis, which has been used for assessing the changes in the salivary protein profile after the interaction with different phenolic compounds. As a result, the reactivity of the different SP and the ability of different phenolic compounds for interacting with SP can be determined. ${ }^{98-100} \mathrm{~A}$ similar approach using liquid chromatography (LC) has been used, allowing the determination of not only the most reactive families of SP, but also the formation of soluble aggregates. ${ }^{27,49}$ LC coupled to mass spectrometry has been used for proteomics studies of the effect of different astringent stimuli on the salivary profile, thus providing qualitative and quantitative information about the interaction. ${ }^{101}$ Moreover, mass spectrometry, namely MALDI-TOF, has also been employed for assessing the identity of phenolic compound-salivary protein soluble aggregates. ${ }^{50,76,77}$

Other recent approaches have studied the interaction process using techniques other than the precipitation of proteins, such as infrared spectroscopy, electronic tongues, fluorescence, nephelometry, dynamic light scattering (DLS), small angle X-ray scattering (SAXS), circular dichroism (CD), nuclear magnetic resonance (NMR) or isothermal titration calorimetry (ITC). Several of these techniques allow studying the interaction even if it does not lead to protein precipitation. For instance, middle infrared spectroscopy (MIR) has been used as a predictive tool for astringency. The studies using MIR assess the most important wavelengths for estimating astringency and they build predictive models by means of chemometric tools, such as partial least square regression (PLS). ${ }^{93,102}$ PLS was also used to build calibration models from near infrared (NIR) spectroscopy results to predict the sensory attributes related to the astringency of grape skin and seed, pointing out the potential of infrared spectroscopy to predict different astringency parameters. ${ }^{103}$ Similarly, electronic tongues based on spectroscopic, potentiometric and/or electrochemical sensors can be used to estimate astringency; these allow making measurements that, when calibrated, have been used to simulate sensory analysis. ${ }^{104}$ The results obtained by using electronic tongues seem promising, allowing the discrimination and classification of wines. ${ }^{105}$ However, although these methodologies usually show good correlations to sensory analysis, they do not provide any information about the astringency process.

Fluorescence quenching measurements study the reduction in the intrinsic fluorescence of proteins (mainly due to the tryptophan residues ${ }^{95}$ ), as a result of the interaction between proteins and phenolic compounds. The study of the fluorescence quenching allows the determination of the extent of the interaction. Results usually show that the higher the concentration of phenolic compounds assayed, the greater the observed quenching effect. ${ }^{106,107}$ However, Ferrer-Gallego et al. (2012) have pointed out that higher phenolic contents do not involve a greater affinity towards proteins since the structural features of the phenolic compounds (molecular size or galloylation in the structure) could modify the affinity, thus affecting quenching results. ${ }^{108}$

Compound astringency can also be assessed by means of nephelometry, which studies the formation of phenolic compound-protein aggregates by measuring the scattered light 
when a beam of light is passed through a solution containing suspended particles. Studies carried out by using this technique show a direct relationship between the level of phenolic compounds and the nephelometric values, ${ }^{108,109}$ which are also related to the ability of phenolic compounds to induce astringency in sensorial analysis. ${ }^{109}$ Nephelometry has also been used to assess the astringency mechanism when an agent for modulating astringency is involved; ${ }^{110}$ however, nephelometry measurements are affected by several factors, but mainly by the size of aggregates since all the particles should be small and of identical size. ${ }^{109}$ Therefore, to avoid the formation of larger aggregates, nephelometry measurements should be done after a short reaction time. DLS could help solving this problem since it measures the relaxation rate of particles in a solution that scatter light, thereby allowing the estimation of their diameter, ${ }^{11}$ providing a size distribution of the aggregates. This technique provides good results, showing a direct relationship between the size of aggregates and the concentration of phenolic compounds assayed, suggesting the formation of complexes or metastable aggregates. ${ }^{74,106}$ The size distribution of the aggregates for a large range of particle sizes can also be studied by SAXS. This technique measures the scattered radiation (X-rays in this case) by a solution containing the aggregates when it is irradiated with an X-ray collimated beam. Measurements are done very close to the primary beam ("small angles") and, depending on the angle, different ranges of aggregate sizes can be studied. ${ }^{111}$ Moreover, this technique allows the obtaining of quantitative information about the strength of the interaction. ${ }^{112}$

Nuclear magnetic resonance (NMR) allows a deeper study of the interaction, since it can provide not only quantitative information, measuring the strength of the interaction, but also qualitative, by providing information about the number and the nature of binding sites. ${ }^{13,114}$ Experiments usually involve a phenolic compound titration, maintaining the protein concentration at a constant value throughout the entire titration. The chemical shifts of protein protons obtained from these experiments are used for obtaining information about the binding sites and the type of aggregate (soluble or insoluble). ${ }^{115}$ The association constants can be obtained from both the chemical shifts ${ }^{113}$ and the saturation transfer difference (STD) experiments. ${ }^{76}$ In the latter, the subtraction of the on-resonance spectrum (in which protein is selectively saturated by irradiating at a region of the spectrum in which protein protons appear) from the off-resonance spectrum (recorded without protein saturation) is done. In the difference spectrum, only the protons of the phenolic compounds that are close to protein via binding will appear, since they could receive saturation transfer from the protein. ${ }^{116}$ This technique also allows the determination of the binding epitope of the phenolic compounds, i.e. the protons of the astringent compound that are closer to the protein upon binding. ${ }^{97,116}$ Moreover, NMR diffusion experiments can be useful for detecting the formation of small aggregates between phenolic compounds and proteins, allowing the determination of the number of binding sites and the association constants by following the changes in the diffusion of the protein throughout the titration. ${ }^{114}$ Structural information about the aggregates (size, binding epitopes in protein and phenolic compound, etc.) can be obtained from two-dimensional NMR experiments, such as TOCSY, NOESY, ROESY, HSQC and DOSY ${ }^{42,115,117}$ Qualitative information about protein-phenolic compound aggregates can also be obtained from circular dichroism (CD) spectroscopy. CD studies the difference in the absorption of the left and right circularly polarized light of the solution containing the protein and/or aggregates, providing information about the bonds and structures responsible for this chirality. ${ }^{118}$ As for studies about astringency, these usually employ the far-ultraviolet (190-370 nm) spectra for obtaining information about the conformational changes in the protein structure as a result of interaction. ${ }^{42,117}$

Concerning the mechanism of aggregation, ITC could be a helpful tool for establishing the main forces driving the interaction. In fact, from the titration curves the changes in energy (enthalpy $(\Delta H)$, Gibbs free energy $(\Delta G)$ and entropy $(\Delta S)$ ) can be determined. Titration at different temperatures helps to distinguish among the different forces driving the interaction. ${ }^{40,41}$ From the values of energy changes, the types of forces involved in the interaction can be ascertained; important $\Delta H$ negative values, i.e., the enthalpy driving the interaction, are related to exothermic hydrogen bonding between protein and phenolic compounds. Hydrophobic interactions can be considered as the main forces of the interaction when the process is entropydriven, i.e., when positive values for $\Delta H$ and for $\Delta S$ are obtained. ${ }^{14,40,41}$ Moreover, from ITC results, the stoichiometry and the binding constants of association can also be obtained, thus helping to assess the whole interaction process.

In addition to these experimental techniques, molecular dynamics (MD) simulations have been employed in order to establish theories about the strength, the mechanisms and the number of molecules involved in the interaction. Calculations are done by using model peptides ${ }^{38,119}$ or salivary peptides ${ }^{97}$ to simulate the interaction with one or several molecules of ligand.

Moreover, it has been pointed out that quantifying only the extent of protein binding is not enough for explaining sensory perception and that it is necessary to also consider other free astringent stimulus in the saliva liquid..$^{65}$ For this reason, new methodologies based on salivary rheology and oral tribology are used to try to explain astringency not only based on protein complexation but in a wider sense. These approaches, which study the modifications in viscosity, friction and lubrication of saliva when mixed with astringent compounds for explaining astringency, ${ }^{120}$ have shown great potential for establishing relationships to the perceived texture and the mouthfeel attributes of different foods. ${ }^{121}$

\section{Oral tribology: adhesion, friction, and lubrication}

Oral tribology is a recent approach that has been proposed as an effective tool for assessing astringency through some lubrication-based textural features. Tribology is a field of study about friction between two interacting surfaces. It can be 
defined as the science of adhesion, friction and lubrication of interacting surfaces that are in relative motion. ${ }^{121}$ The main factor in tribology studies is the friction coefficient, i.e., the ratio between the measured friction force and the normal load. ${ }^{122}$ This coefficient can be used for obtaining quantitative information about the nature of the interactions between the different surfaces involved, since it depends on the surface roughness and geometry. When a lubricant such as saliva is present, the friction coefficient indicates the lubrication status between the two surfaces. ${ }^{123}$ Thus, since the lubricating ability of salivary proteins can be reduced due to the interaction with phenolic compounds, the study of friction and oral lubrication can be very useful for unraveling the astringency perception induced by wine phenols.

Friction-based mechanisms are based on the precipitation of proteins from salivary film, an "immobile" layer of saliva on the tongue and palate surfaces that does not actively participate in oral processing. ${ }^{123}$ As a result of precipitation, the lubricating properties of saliva can be reduced due to a loss of viscosity and, in addition, the precipitate by itself (the particles formed) can increase the friction between the surfaces in contact. $^{124}$ However, in oral tribology studies, the interaction between salivary proteins and phenolic compounds as well as the effects of other wine components such as ethanol or other wine alcohols should be considered, since these compounds also modify the rheological properties of saliva (like viscosity) and therefore its ability for lubrication. ${ }^{122}$

Due to the factors mentioned above, oral tribology has been used for assessing sensory perception from an objective point of view. It has been reported that a significant increase in friction coefficient occurs upon exposure to solutions of epigallocatechin or its galloylated derivative, ${ }^{125}$ and this increase is also related to the concentration of the phenolic compound; however, this trend is not observed for all phenolic compounds. For instance, although epicatechin solutions have been perceived to be astringent, epicatechin does not affect the lubricating properties of the salivary film, i.e. it does not affect the friction coefficient. ${ }^{125}$ More recently, Brossard et $a{ }^{120}{ }^{120}$ studied both the effect of the grape variety employed in winemaking on the friction coefficient and the relationship between the sensory perception of different astringent compounds or wines and the friction coefficient. These authors found that differences in the friction coefficient obtained when the different wines were tasted can be related to the phenolic composition of those wines. Moreover, they found a significant correlation between the perceived astringency and the friction coefficient determined, which could be indicative of the usefulness of oral tribology for estimating astringency.

\section{Conclusions}

Despite the importance of astringency in the quality of red wines, and therefore its economic importance in the winemaking industry, the mechanisms of astringency are still not well understood. This knowledge is essential to successfully deal with processes of modulation of astringency in wineries in a non-empirical way (for example using biopolymers such as mannoproteins). Several aspects that have been outlined in this review, such as the existence of synergisms of astringency, the utilization of new methodologies as molecular dynamics simulations, tribology and the application of instrumental techniques to unravel the astringency mechanisms and/or to predict the astringency sensations elicited by different compounds, may allow the provision of an objective explanation for the astringency of different food and beverages such as wines.

\section{Conflicts of interest}

There are no conflicts to declare.

\section{Acknowledgements}

The authors thank the Spanish MINECO (Project ref. AGL201458486-C2-1-R and AGL2017-84793-C2-1-R co-funded by FEDER). IGE thanks FEDER-Interreg España-Portugal Programme (Project ref. 0377_IBERPHENOL_6_E) for postdoctoral contract and AMRP thanks MINECO for FPI scholarship. a interreg

\section{References}

1 ASTM, Standard Definitions of Terms Relating to Sensory Evaluation of Materials and Products, American Society for Testing and Materials, Philadephia, 2004.

2 M. R. Bajec and G. J. Pickering, Astringency: Mechanisms and perception, Crit. Rev. Food Sci. Nutr., 2008, 48(9), 858875.

3 M. A. Joslyn and J. L. Goldstein, Astringency of Fruits and Fruit Products in Relation to Phenolic Content, Adv. Food Res., 1964, 13, 179-217.

4 E. C. Bate-Smith, Astringency in foods, Food Process. Packag., 1954, 23, 124-127.

5 E. C. Bate-Smith, Haemanalysis of tannins: The concept of relative astringency, Phytochemistry, 1973, 12(4), 907912.

6 C. B. Lee and H. T. Lawless, Time-course of astringent sensations, Chem. Senses, 1991, 16(3), 225-238.

7 B. G. Green, Oral astringency: A tactile component of flavor, Acta Psychol., 1993, 84(1), 119-125.

8 N. J. Baxter, T. H. Lilley, E. Haslam and M. P. Williamson, Multiple interactions between polyphenols and a salivary proline-rich protein repeat result in complexation and precipitation, Biochemistry, 1997, 36(18), 5566-5577.

9 K. J. Siebert, N. V. Troukhanova and P. Y. Lynn, Nature of Polyphenol - Protein Interactions, J. Agric. Food Chem., 1996, 44, 80-85. 
10 S. Soares, N. Mateus and V. de Freitas, Interaction of different classes of salivary proteins with food tannins, Food Res. Int., 2012, 49(2), 807-813.

11 A. J. Charlton, N. J. Baxter, M. L. Khan, A. J. G. Moir, E. Haslam, A. P. Davies and M. P. Williamson, Polyphenol/peptide binding and precipitation, J. Agric. Food Chem., 2002, 50(6), 1593-1601.

12 E. Jöbstl, J. O'Connell, J. P. A. Fairclough and M. P. Williamson, Molecular model for astringency produced by polyphenol/protein interactions, Biomacromolecules, 2004, 5(3), 942-949.

13 R. Ferrer-Gallego, J. M. Hernández-Hierro, J. C. RivasGonzalo and M. T. Escribano-Bailón, Sensory evaluation of bitterness and astringency sub-qualities of wine phenolic compounds: Synergistic effect and modulation by aromas, Food Res. Int., 2014, 62, 1100-1107.

14 A. M. Ramos-Pineda, I. García-Estévez, N. F. Brás, E. M. Martín Del Valle, M. Dueñas and M. T. Escribano Bailón, Molecular Approach to the Synergistic Effect on Astringency Elicited by Mixtures of Flavanols, J. Agric. Food Chem., 2017, 65(31), 6425-6433.

15 C. A. Lee and Z. M. Vickers, Astringency of Foods May Not be Directly Related to Salivary Lubricity, J. Food Sci., 2012, 77(9), 302-306.

16 C. A. Lee, B. Ismail and Z. M. Vickers, The Role of Salivary Proteins in the Mechanism of Astringency, J. Food Sci., 2012, 77(4), C381-C387.

17 H. Tachibana, K. Koga, Y. Fujimura and K. Yamada, A receptor for green tea polyphenol EGCG, Nat. Struct. Mol. Biol., 2004, 11(4), 380-381.

18 C. Payne, P. K. Bowyer, M. Herderich and S. E. P. Bastian, Interaction of astringent grape seed procyanidins with oral epithelial cells, Food Chem., 2009, 115(2), 551557.

19 H. L. Gibbins and G. H. Carpenter, Alternative mechanisms of astringency - What is the role of saliva?, J. Texture Stud., 2013, 44(5), 364-375.

20 N. L. Huq, K. J. Cross, M. Ung, H. Myroforidis, P. D. Veith, D. Chen, D. Stanton, H. He, B. R. Ward and E. C. Reynolds, A review of the salivary proteome and peptidome and saliva-derived peptide therapeutics, Int. J. Pept. Res. Ther., 2007, 13(4), 547-564.

21 I. Messana, R. Inzitari, C. Fanali, T. Cabras and M. Castagnola, Facts and artifacts in proteomics of body fluids. What proteomics of saliva is telling us?, J. Sep. Sci., 2008, 31(11), 1948-1963.

22 R. Gawel, Red wine astringency: a review, Aust. J. Grape Wine Res., 1998, 4(2), 74-95.

23 B. Manconi, M. Castagnola, T. Cabras, A. Olianas, A. Vitali, C. Desiderio, M. T. Sanna and I. Messana, The intriguing heterogeneity of human salivary proline-rich proteins: Short title: Salivary proline-rich protein species, J. Proteomics, 2016, 134, 47-56.

24 R. Inzitari, T. Cabras, D. V. Rossetti, C. Fanali, A. Vitali, M. Pellegrini, G. Paludetti, A. Manni, B. Giardina, I. Messana, et al., Detection in human saliva of different statherin and P-B fragments and derivatives, Proteomics, 2006, 6(23), 6370-6379.

25 A. Bennick, Interaction of Plant Polyphenols with Salivary Proteins, Crit. Rev. Oral Biol. Med., 2002, 13(2), 184-196.

26 Y. Lu and A. Bennick, Interaction of tannin with human salivary proline-rich proteins, Arch. Oral Biol., 1998, 43(9), 717-728.

27 N. Quijada-Morín, C. Crespo-Expósito, J. C. RivasGonzalo, I. García-Estévez and M. T. Escribano-Bailón, Effect of the addition of flavan-3-ols on the HPLC-DAD salivary-protein profile, Food Chem., 2016, 207, 272-278.

28 S. Soares, R. Vitorino, H. Osório, A. Fernandes, A. Venâncio, N. Mateus, F. Amado and V. De Freitas, Reactivity of human salivary proteins families toward food polyphenols, J. Agric. Food Chem., 2011, 59(10), 55355547.

29 E. Brandão, S. Soares, N. Mateus and V. De Freitas, In vivo interactions between procyanidins and human saliva proteins: Effect of repeated exposures to procyanidins solution, J. Agric. Food Chem., 2014, 62(39), 9562-9568.

30 A. Rinaldi, A. Gambuti and L. Moio, Application of the SPI (Saliva Precipitation Index) to the evaluation of red wine astringency, Food Chem., 2012, 135(4), 2498-2504.

31 B. Sun, M. D. Sá, C. Leandro, I. Caldeira, F. L. Duarte and I. Spranger, Reactivity of polymeric proanthocyanidins toward salivary proteins and their contribution to young red wine astringency, J. Agric. Food Chem., 2013, 61(4), 939-946.

32 R. Ferrer-Gallego, R. Gonçalves, J. C. Rivas-Gonzalo, M. T. Escribano-Bailón and V. De Freitas, Interaction of phenolic compounds with bovine serum albumin (BSA) and $\alpha$-amylase and their relationship to astringency perception, Food Chem., 2012, 135(2), 651-658.

33 M. C. Llaudy, R. Canals, J.-M. Canals, N. Rozés, L. Arola and F. Zamora, New Method for Evaluating Astringency in Red Wine, J. Agric. Food Chem., 2004, 52(4), 742-746.

34 E. Jöbstl, J. R. Howse, J. P. A. Fairclough and M. P. Williamson, Noncovalent cross-linking of casein by epigallocatechin gallate characterized by single molecule force microscopy, J. Agric. Food Chem., 2006, 54(12), 40774081.

35 H. Oh, J. E. Hoff, G. S. Armstrong and L. A. Haff, Hydrophobic Interaction in Tannin-Protein Complexes, J. Agric. Food Chem., 1980, 28(2), 394-398.

36 N. J. Murray, M. P. Williamson, T. H. Lilley and E. Haslam, Study of the interaction between salivary proline-rich proteins and a polyphenol by $1 \mathrm{H}-\mathrm{NMR}$ spectroscopy, Eur. J. Biochem., 1994, 219(3), 923-935.

37 F. Canon, F. Paté, V. Cheynier, P. Sarni-Manchado, A. Giuliani, J. Pérez, D. Durand, J. Li and B. Cabane, Aggregation of the salivary proline-rich protein IB5 in the presence of the tannin EgCG, Langmuir, 2013, 29(6), 19261937.

38 O. Cala, E. J. Dufourc, E. Fouquet, C. Manigand, M. Laguerre and I. Pianet, The colloidal state of tannins impacts the nature of their interaction with proteins: The 
case of salivary proline-rich protein/procyanidins binding, Langmuir, 2012, 28(50), 17410-17418.

39 B. Kalyanaraman, P. I. Premovic and R. C. Sealy, Semiquinone anion radicals from addition of amino acids, peptides, and proteins to quinones derived from oxidation of catechols and catecholamines. An ESR spin stabilization study, J. Biol. Chem., 1987, 262(23), 11080-11087.

40 J. M. McRae, R. J. Falconer and J. A. Kennedy, Thermodynamics of grape and wine tannin interaction with polyproline: Implications for red wine astringency, J. Agric. Food Chem., 2010, 58(23), 12510-12518.

41 R. L. Kilmister, P. Faulkner, M. O. Downey, S. J. Darby and R. J. Falconer, The complexity of condensed tannin binding to bovine serum albumin - An isothermal titration calorimetry study, Food Chem., 2016, 190, 173-178.

42 C. Simon, K. Barathieu, M. Laguerre, J. M. Schmitter, E. Fouquet, I. Pianet and E. J. Dufourc, Three-dimensional structure and dynamics of wine tannin-saliva protein complexes. A multitechnique approach, Biochemistry, 2003, 42(35), 10385-10395.

43 S. Soares, I. García-Estévez, R. Ferrer-Galego, N. F. Brás, E. Brandão, M. Silva, N. Teixeira, F. Fonseca, S. F. Sousa, F. Ferreira-da-Silva, et al., Study of human salivary prolinerich proteins interaction with food tannins, Food Chem., 2018, 243, 175-185.

44 M. S. Silva, I. García-Estévez, E. Brandão, N. Mateus, V. De Freitas and S. Soares, Molecular Interaction between Salivary Proteins and Food Tannins, J. Agric. Food Chem., 2017, 65(31), 6415-6424.

45 P. Sarni-Manchado, J. M. Canals-Bosch, G. Mazerolles and V. Cheynier, Influence of the glycosylation of human salivary proline-rich proteins on their interactions with condensed tannins, J. Agric. Food Chem., 2008, 56(20), 95639569.

46 D. Rossetti, G. E. Yakubov, J. R. Stokes, A. M. Williamson and G. G. Fuller, Interaction of human whole saliva and astringent dietary compounds investigated by interfacial shear rheology, Food Hydrocolloids, 2008, 22(6), 10681078.

47 E. Obreque-Slier, R. Lopez-Solis, Á. Peña-Neira and F. Zamora-Marín, Tannin-protein interaction is more closely associated with astringency than tannin-protein precipitation: Experience with two oenological tannins and a gelatin, Int. J. Food Sci. Technol., 2010, 45(12), 26292636.

48 J. C. Hufnagel and T. Hofmann, Quantitative reconstruction of the nonvolatile sensometabolome of a red wine, J. Agric. Food Chem., 2008, 56(19), 9190-9199.

49 S. Kallithraka, J. Bakker and M. N. Clifford, Evidence that salivary proteins are involved in astringency, J. Sens. Stud., 1998, 13(1), 29-43.

50 M. R. Pérez-Gregorio, N. Mateus and V. De Freitas, Rapid screening and identification of new soluble tannin-salivary protein aggregates in saliva by mass spectrometry (MALDI-TOF-TOF and FIA-ESI-MS), Langmuir, 2014, 30(28), 8528-8537.
51 M. R. Pérez-Gregorio, N. Mateus and V. De Freitas, New procyanidin B3-human salivary protein complexes by mass spectrometry. Effect of salivary protein profile, tannin concentration, and time stability, J. Agric. Food Chem., 2014, 62(41), 10038-10045.

52 S. Soares, A. Sousa, N. Mateus and V. De Freitas, Effect of condensed tannins addition on the astringency of red wines, Chem. Senses, 2012, 37(2), 191-198.

53 O. Cala, S. Fabre, N. Pinaud, E. J. Dufourc, E. Fouquet, M. Laguerre and I. Pianet, Towards a molecular interpretation of astringency: Synthesis, 3D structure, colloidal state, and human saliva protein recognition of procyanidins, Planta Med., 2011, 77(11), 1116-1122.

54 R. Ferrer-Gallego, N. Quijada-Morín, N. F. Brás, P. Gomes, V. de Freitas, J. C. Rivas-Gonzalo and M. T. EscribanoBailón, Characterization of sensory properties of flavanols-A molecular dynamic approach, Chem. Senses, 2015, 40(6), 381-390.

55 V. De Freitas and N. Mateus, Nephelometric study of salivary protein-tannin aggregates, J. Sci. Food Agric., 2002, 82(1), 113-119.

56 N. Quijada-Morín, J. Regueiro, J. Simal-Gándara, E. Tomás, J. C. Rivas-Gonzalo and M. T. Escribano-Bailón, Relationship between the sensory-determined astringency and the flavanolic composition of red wines, J. Agric. Food Chem., 2012, 60(50), 12355-12361.

57 H. Peleg, K. Gacon, P. Schlich and A. C. Noble, Bitterness and astringency of flavan-3-ol monomers, dimers and trimers, J. Sci. Food Agric., 1999, 79(8), 1123-1128.

58 S. Soares, N. Mateus and V. De Freitas, Interaction of different polyphenols with Bovine Serum Albumin (BSA) and Human Salivary $\alpha$-Amylase (HSA) by fluorescence quenching, J. Agric. Food Chem., 2007, 55(16), 6726-6735.

59 S. Soares, I. García-Estévez, R. Ferrer-Galego, N. F. Brás, E. Brandão, M. Silva, N. Teixeira, F. Fonseca, S. F. Sousa, F. Ferreira-da-Silva, et al., Study of human salivary prolinerich proteins interaction with food tannins, Food Chem., 2018, 243, 175-185.

60 S. Scharbert, M. Jezussek and T. Hofmann, Evaluation of the taste contribution of theaflavins in black tea infusions using the taste activity concept, Eur. Food Res. Technol., 2004, 218(5), 442-447.

61 A. J. Charlton, E. Haslam and M. P. Williamson, Multiple conformations of the proline-rich protein/epigallocatechin gallate complex determined by time-averaged nuclear Overhauser effects, J. Am. Chem. Soc., 2002, 124(33), 98999905.

62 C. Poncet-Legrand, C. Gautier, V. Cheynier and A. Imberty, Interactions between flavan-3-ols and poly(L-proline) studied by isothermal titration calorimetry: Effect of the tannin structure, J. Agric. Food Chem., 2007, 55(22), 92359240.

$63 \mathrm{M}$. Li and A. E. Hagerman, Role of the flavan-3-ol and galloyl moieties in the interaction of (-)-epigallocatechin gallate with serum albumin, J. Agric. Food Chem., 2014, 62(17), 3768-3775. 
64 V. De Freitas and N. Mateus, Structural features of procyanidin interactions with salivary proteins, J. Agric. Food Chem., 2001, 49(2), 940-945.

65 B. Schwarz and T. Hofmann, Is there a direct relationship between oral astringency and human salivary protein binding?, Eur. Food Res. Technol., 2008, 227(6), 1693-1698.

66 R. Ferrer-Gallego, N. Quijada-Morín, N. F. Brás, P. Gomes, V. de Freitas, J. C. Rivas-Gonzalo and M. T. EscribanoBailón, Characterization of sensory properties of flavanols-A molecular dynamic approach, Chem. Senses, 2015, 40(6), 381-390.

67 J. R. Bacon and M. J. C. Rhodes, Development of a Competition Assay for the Evaluation of the Binding of Human Parotid Salivary Proteins to Dietary Complex Phenols and Tannins Using a Peroxidase-Labeled Tannin, J. Agric. Food Chem., 1998, 46(12), 5083-5088.

68 T. Hofman, A. Glabasnia, B. Schwarz, K. N. Wiseman, K. A. Gangwer and A. E. Hagerman, Protein binding \& astringent taset of a polymeric procyanidin, 1,2,3,6-pentaO-galloyl-B-D-glycopyranose castalagin, and grandinin, J. Agric. Food Chem., 2006, 54, 9503-9509.

69 J. R. Bacon and M. J. C. Rhodes, Binding affinity of hydrolyzable tannins to parotid saliva and to proline-rich proteins derived from it, J. Agric. Food Chem., 2000, 48(3), 838-843.

70 M. R. González-Centeno, K. Chira and P. L. Teissedre, Ellagitannin content, volatile composition and sensory profile of wines from different countries matured in oak barrels subjected to different toasting methods, Food Chem., 2016, 210, 500-511.

71 A. Glabasnia and T. Hofmann, Sensory-directed identification of taste-active ellagitannins in American (Quercus alba L.) and European oak wood (Quercus robur L.) and quantitative analysis in bourbon whiskey and oak-matured red wines, J. Agric. Food Chem., 2006, 54(9), 3380-3390.

72 A. Troszyńska, I. Estrella, G. Lamparski, T. Hernández, R. Amarowicz and R. B. Pegg, Relationship between the sensory quality of lentil (Lens culinaris) sprouts and their phenolic constituents, Food Res. Int., 2011, 44(10), 3195-3201.

73 J. Xiao, M. Suzuki, X. Jiang, K. Yamamoto, F. Ren and $\mathrm{M}$. Xu, Influence of B-Ring Hydroxylation on Interactions of Flavonols with Bovine Serum Albumin Influence of B-Ring Hydroxylation on Interactions of Flavonols with Bovine Serum Albumin, Society, 2008, 56(7), 2350-2356.

74 R. Ferrer-Gallego, N. F. Brás, I. García-Estévez, N. Mateus, J. C. Rivas-Gonzalo, V. de Freitas and M. T. EscribanoBailón, Effect of flavonols on wine astringency and their interaction with human saliva, Food Chem., 2016, 209, 358-364.

75 S. Vidal, L. Francis, A. Noble, M. Kwiatkowski, V. Cheynier and E. Waters, Taste and mouth-feel properties of different types of tannin-like polyphenolic compounds and anthocyanins in wine, Anal. Chim. Acta, 2004, 513(1), 57-65.

76 R. Ferrer-Gallego, S. Soares, N. Mateus, J. C. Rivas-Gonzalo, M. T. Escribano-Bailón and V. De Freitas, New
Anthocyanin-Human Salivary Protein Complexes, Langmuir, 2015, 31(30), 8392-8401.

77 I. García-Estévez, L. Cruz, J. Oliveira, N. Mateus, V. de Freitas and S. Soares, First evidences of interaction between pyranoanthocyanins and salivary proline-rich proteins, Food Chem., 2017, 228, 574-581.

78 R. Ferrer-Gallego, J. M. Hernández-Hierro, J. C. RivasGonzalo and M. T. Escribano-Bailón, Sensory evaluation of bitterness and astringency sub-qualities of wine phenolic compounds: Synergistic effect and modulation by aromas, Food Res. Int., 2014, 62, 1100-1107.

79 H. Kawamoto, Effects of Environmental Factors on TwoStage Tannin-Protein Co-Precipitation, Phytochemistry, 1997, 46(3), 479-483.

80 J. M. McRae and J. A. Kennedy, Wine and grape tannin interactions with salivary proteins and their impact on astringency: A review of current research, Molecules, 2011, 16(3), 2348-2364.

81 H. Fontoin, C. Saucier, P. L. Teissedre and Y. Glories, Effect of $\mathrm{pH}$, ethanol and acidity on astringency and bitterness of grape seed tannin oligomers in model wine solution, Food Qual. Prefer., 2008, 19(3), 286-291.

82 E. Obreque-Slier, Á. Peña-Neira and R. López-Solís, Interactions of enological tannins with the protein fraction of saliva and astringency perception are affected by pH, LWT-Food Sci. Technol., 2012, 45(1), 88-93.

83 C. Poncet-Legrand, D. Cartalade, J. L. Putaux, V. Cheynier and A. Vernhet, Flavan-3-ol aggregation in model ethanolic solutions: Incidence of polyphenol structure, concentration, ethanol content, and ionic strength, Langmuir, 2003, 19(25), 10563-10572.

84 A. A. Watrelot, D. L. Schulz and J. A. Kennedy, Wine polysaccharides influence tannin-protein interactions, Food Hydrocolloids, 2017, 63, 571-579.

85 N. Mateus, E. Carvalho, C. Lu and V. de Freitas, Influence of the tannin structure on the disruption effect of carbohydrates on protein - tannin aggregates, Anal. Chim. Acta, 2004, 513, 135-140.

86 C. Le Bourvellec, B. Bouchet and C. M. Renard, Noncovalent interaction between procyanidins and apple cell wall material. Part III: Study on model polysaccharides, Biochim. Biophys. Acta, Gen. Subj., 2005, 1725(1), 10-18.

87 E. Brandão, M. S. Silva, I. García-Estévez, P. Williams, N. Mateus, T. Doco, V. de Freitas and S. Soares, The role of wine polysaccharides on salivary protein-tannin interaction: A molecular approach, Carbohydr. Polym., 2017, 177, 77-85.

88 I. García-Estévez, R. Pérez-Gregorio, S. Soares, N. Mateus and V. de Freitas, Oenological perspective of red wine astringency, OENO One, 2017, 51(2), 1-19.

89 B. G. Green, P. Dalton, B. Cowart, G. Shaffer, K. Rankin and J. Higgins, Evaluating the "Labeled Magnitude Scale" for measuring sensations of taste and smell, Chem. Senses, 1996, 21(3), 323-334.

90 G. J. Pickering, K. Simunkova and D. DiBattista, Intensity of taste and astringency sensations elicited by red wines is 
associated with sensitivity to PROP (6-n-propylthiouracil), Food Qual. Prefer., 2004, 15(2), 147-154.

91 R. Gawel, A. Oberholster and I. L. Francis, A "Mouth-feel Wheel": terminology for communicating the mouth-feel characteristics of red wine, Aust. J. Grape Wine Res., 2000, 6(3), 203-207.

92 M. Cliff, N. Brau, M. King and G. Mazza, Development of predictive models for astringency from anthocyanin, phenolic and coloranalyses of British Columbia red wines, J. Int. Sci. Vigne Vin, 2002, 36(1), 21-30.

93 A. M. Simoes Costa, M. M. Costa Sobral, I. Delgadillo, A. Cerdeira and A. Rudnitskaya, Astringency quantification in wine: Comparison of the electronic tongue and FT-MIR spectroscopy, Sens. Actuators, B, 2015, 207, 1095-1103.

94 M. C. Goldner and M. C. Zamora, Effect of polyphenol concentrations on astringency perception and its correlation with gelatin index of red wine, J. Sens. Stud., 2010, 25(5), 761-777.

95 S. I. Soares, R. M. Gonçalves, I. Fernandes, N. Mateus and V. De Freitas, Mechanistic approach by which polysaccharides inhibit $\alpha$-amylase/ procyanidin aggregation, J. Agric. Food Chem., 2009, 57(10), 4352-4358.

96 T. Hofmann, A. Glabasnia, B. Schwarz, K. N. Wisman, K. A. Gangwer and A. E. Hagerman, Protein binding and astringent taste of a polymeric procyanidin, 1,2,3,4,6penta-O-galloyl- $\beta$-D-glucopyranose, castalagin, and grandinin, J. Agric. Food Chem., 2006, 54(25), 9503-9509.

97 S. Soares, E. Brandão, N. Mateus and V. de Freitas, Sensorial properties of red wine polyphenols: Astringency and bitterness, Crit. Rev. Food Sci. Nutr., 2017, 57(5), 937-948.

98 A. Gambuti, A. Rinaldi, R. Pessina and L. Moio, Evaluation of aglianico grape skin and seed polyphenol astringency by SDS-PAGE electrophoresis of salivary proteins after the binding reaction, Food Chem., 2006, 97(4), 614-620.

99 A. Rinaldi, A. Gambuti, V. Moine-Ledoux and L. Moio, Evaluation of the astringency of commercial tannins by means of the SDS-PAGE-based method, Food Chem., 2010, 122(4), 951-956.

100 P. Sarni-Manchado, V. Cheynier and M. Moutounet, Interactions of grape seed tannins with salivary proteins, J. Agric. Food Chem., 1999, 47(1), 42-47.

101 J. Delius, G. Médard, B. Kuster and T. Hofmann, Effect of Astringent Stimuli on Salivary Protein Interactions Elucidated by Complementary Proteomics Approaches, J. Agric. Food Chem., 2017, 65(10), 2147-2154.

102 L. Vera, L. Aceña, R. Boqué, J. Guasch, M. Mestres and O. Busto, Application of an electronic tongue based on FT-MIR to emulate the gustative mouthfeel "tannin amount" in red wines, Anal. Bioanal. Chem., 2010, (397), 3043-3049.

103 R. Ferrer-Gallego, J. M. Hernández-Hierro, J. C. RivasGonzalo and M. T. Escribano-Bailón, Evaluation of sensory parameters of grapes using near infrared spectroscopy, J. Food Eng., 2013, 118(3), 333-339.

104 C. Diako, K. McMahon, S. Mattinson, M. Evans and C. Ross, Alcohol, Tannins, and Mannoprotein and their
Interactions Influence the Sensory Properties of Selected Commercial Merlot Wines: A Preliminary Study, J. Food Sci., 2016, 81(8), S2039-S2048.

105 M. Gay, C. Apetrei, I. Nevares, M. Del Alamo, J. Zurro, N. Prieto, J. A. De Saja and M. L. Rodríguez-Méndez, Application of an electronic tongue to study the effect of the use of pieces of wood and micro-oxygenation in the aging of red wine, Electrochim. Acta, 2010, 55(22), 6782-6788.

106 P. Jauregi, J. B. Olatujoye, I. Cabezudo, R. A. Frazier and M. H. Gordon, Astringency reduction in red wine by whey proteins, Food Chem., 2016, 199, 547-555.

107 J. W. Yao, C. J. Lin, G. Y. Chen, F. Lin and T. Tao, The interactions of epigallocatechin-3-gallate with human whole saliva and parotid saliva, Arch. Oral Biol., 2010, 55(7), 470-478.

108 R. Ferrer-Gallego, R. Gonçalves, J. C. Rivas-Gonzalo, M. T. Escribano-Bailón and V. De Freitas, Interaction of phenolic compounds with bovine serum albumin (BSA) and $\alpha$-amylase and their relationship to astringency perception, Food Chem., 2012, 135(2), 651-658.

109 E. Monteleone, N. Condelli, C. Dinnella and M. Bertuccioli, Prediction of perceived astringency induced by phenolic compounds, Food Qual. Prefer., 2004, 15(7), 761-769.

110 E. Brandão, M. Santos Silva, I. García-Estévez, N. Mateus, V. de Freitas and S. Soares, Molecular study of mucin-procyanidin interaction by fluorescence quenching and Saturation Transfer Difference (STD)-NMR, Food Chem., 2017, 228, 427-434.

111 M. V. Petoukhov and D. I. Svergun, Applications of smallangle X-ray scattering to biomacromolecular solutions, Int. J. Biochem. Cell Biol., 2013, 45(2), 429-437.

112 C. Pascal, C. Poncet-legrand, B. Cabane and A. Vernhet, Aggregation of a Proline-Rich Protein Induced by Epigallocatechin Gallate and Condensed Tannins: Effect of Protein Glycosylation., J. Agric. Food Chem., 2008, 67246732.

113 O. Cala, N. Pinaud, C. Simon, E. Fouquet, M. Laguerre, E. J. Dufourc and I. Pianet, NMR and molecular modeling of wine tannins binding to saliva proteins: revisiting astringency from molecular and colloidal prospects, FASEB J., 2010, 24(11), 4281-4290.

114 O. Cala, S. Fabre, E. Fouquet, E. J. Dufourc and I. Pianet, NMR of human saliva protein/wine tannin complexes. Towards deciphering astringency with physico-chemical tools, C. R. Chim., 2010, 13(4), 449-452.

115 B. Faurie, E. J. Dufourc, M. Laguerre and I. Pianet, Monitoring the Interactions of a Ternary Complex Using NMR Spectroscopy: The Case of Sugars, Polyphenols, and Proteins, Anal. Chem., 2016, 88(24), 12470-12478.

116 A. Viegas, J. Manso, F. L. Nobrega and E. J. Cabrita, Saturation-transfer difference (STD) NMR: A simple and fast method for ligand screening and characterization of protein binding, J. Chem. Educ., 2011, 88(7), 990-994.

117 C. Pascal, F. Paté, V. Cheynier and M. A. Delsuc, Study of the interactions between a proline-rich protein and a 
flavan-3-ol by NMR: Residual structures in the natively unfolded protein provides anchorage points for the ligands, Biopolymers, 2009, 91(9), 745-756.

118 A. Rodger, R. Marrington, D. Roper and S. Windsor, Circular dichroism spectroscopy for the study of proteinligand interactions, Methods Mol. Biol., 2005, 305, 343364.

119 R. Ferrer-Gallego, J. M. Hernández-Hierro, N. F. Brás, N. Vale, P. Gomes, N. Mateus, V. de Freitas, F. J. Heredia and M. T. Escribano-Bailón, Interaction between Wine Phenolic Acids and Salivary Proteins by SaturationTransfer Difference Nuclear Magnetic Resonance Spectroscopy (STD-NMR) and Molecular Dynamics Simulations, J. Agric. Food Chem., 2017, 65(31), 6434-6441.

120 N. Brossard, H. Cai, F. Osorio, E. Bordeu and J. Chen, "Oral" Tribological Study on the Astringency Sensation of Red Wines, J. Texture Stud., 2016, 47(5), 392-402.
121 R. Upadhyay, N. Brossard and J. Chen, Mechanisms underlying astringency: Introduction to an oral tribology approach, J. Phys. D: Appl. Phys., 2016, 49(10), 104003.

122 L. Laguna, B. Bartolomé and M. V. Moreno-Arribas, Mouthfeel perception of wine: Oral physiology, components and instrumental characterization, Trends Food Sci. Technol., 2017, 59, 49-59.

123 S. Prakash, From Rheology to Tribology: Applications of Tribology in Studying Food Oral Processing and Texture Perception, Adv. Food Rheol. Its Appl., 2016, 54(2), 65-86.

124 R. A. De Wijk and J. F. Prinz, Mechanisms Underlying the Role of Friction in Oral Texture, J. Texture Stud., 2006, 31, 413-427.

125 D. Rossetti, J. H. H. Bongaerts, E. Wantling, J. R. Stokes and A. M. Williamson, Astringency of tea catechins: More than an oral lubrication tactile percept, Food Hydrocolloids, 2009, 23(7), 1984-1992. 